treatment can lead to disseminated disease and systemic complications. ${ }^{22}$

Primary muscle abscess is a rare condition but must be considered as a cause of muscle pain especially around the hip.

1 Christin L, Sarosi GA. Pyomyositis in North America: case reports and review. Clin Infect Dis 1992;15:668-77.

2 Hall RL, Callaghan JJ, Moloney E, Martinez S, Harrelson

JM. Pyomyositis in a temperate climate: presentation, diagnosis and treatment. J Bone Joint Surg (Am) 1990;72: nosis and

3 Steinig JP, Odom JW, Jurgenson PF, Williams JS. Tropical pyomyositis. J Med Assoc Georgia 1992;81:75-6.

4 Gambir IS, Singh DS, Gupta SS, Gupta PR, Kumar M Tropical pyomyositis in India: a clinico-histopathological study. J Trop Med Hyg 1992;95:42-6.

5 Renwick SE, Ritterbusch JF. Pyomyositis in children. J Pediatr Orthop 1993;13:769-72.

6 Brown RL. Pyomyositis in patients with diabetes. Com puted tomography as a key to diagnosis. Postgrad Med 1989;86:79-81.

7 Rodgers WB, Yodlowski ML, Mintzer CM. Pyomyositis in patients who have the human immunodeficiency virus. Case report and review of the literature. J Bone Joint Surg (Am) 1993;75:588-92.

8 Rygnestad T, Kvam AM. Streptococcal myositis and tissue necrosis with intramuscular administration of diclofenac (Voltaren). Acta Anaesthesiol Scand 1995;39:1128-30.

9 Michaels BM, Orgill DP, Santos AA. Tropical pyomyositis presenting in the upper extremity. Arch Surg 1995;130:
$446-7$.
10 Flory P, Brocq O, Euller-Ziegler L, Ziegler G. Pyomyositis: cervical localisation. J Rheumatol 1993;20:1411-3.

11 Huang DY. Tuberculous muscle abscess: an unusual presentation of tuberculosis. Am J Med 1990;88:57-9N.

12 Martin J, Marco V, Zidan A, Marco C. Hydatid disease of the soft tissues of the lower limb: findings in three cases. Skel Radiol 1993;22:511-4.

13 Gill MV, Cunha BA. Nocardia asteroides buttock abscess. Infection 1995;23:126-7.

14 Armstrong DG, D'Amato CR, Strong ML. Three cases of staphylococcal pyomyositis in adolescence, including one patient with neurologic compromise. J Pediatr Orthop 1993;13:452-5.

15 Peetermans WE, Buyse B, Vanhoof J. Pyogenic abscess of the gluteal muscle due to Streptococcus pneumoniae the gluteal muscle due to Streptococcus promment]. Clin Infect Dis 1993;17:939.

16 Chen WS. Sciatica due to piriformis pyomyositis. Report of a case. J Bone Joint Surg (Am) 1992;74:1546-8.

17 Pai VS, Yee E, Lawson D, Curtis G. Iliacus pyomyositis with involvement of lateral cutaneous nerve of the thigh. NZ involvement of lateral

18 Applegate GR, Cohen AJ. Pyomyositis: early detection utilizing multiple imaging modalities. Magn Reson Imag ing 1991;9:187-93.

19 Schiff RG, Silver L. Tropical pyomyositis. Demonstration of extent and distribution of disease by gallium scintigraphy. Clin Nuclear Med 1990;15:542-4.

20 Gordon BA, Martinez S, Collins AJ. Pyomyositis: characteristics at CT and MR imaging. Radiology 1995;197:27986.

21 Hopkins KL, Li KC, Bergman G. Gadolinium-DTPAenhanced magnetic resonance imaging of musculoskeletal infectious processes. Skel Radiol 1995;24:325-30.

22 McGill PE. Bacterial infections: pyomyositis. Baillieres Clin Rheumatol 1995;9:193-200.

\title{
Malignant hypertension presenting as blurred vision in a 43 year old intravenous drug abuser
}

\section{Department of \\ Ophthalmology, St \\ James' University \\ Hospital, Beckett \\ Street, Leeds LS9 7TF \\ G Walters}

T R Dabbs

Correspondence to: Mr G Walters.

Accepted for publication 6 February 1997

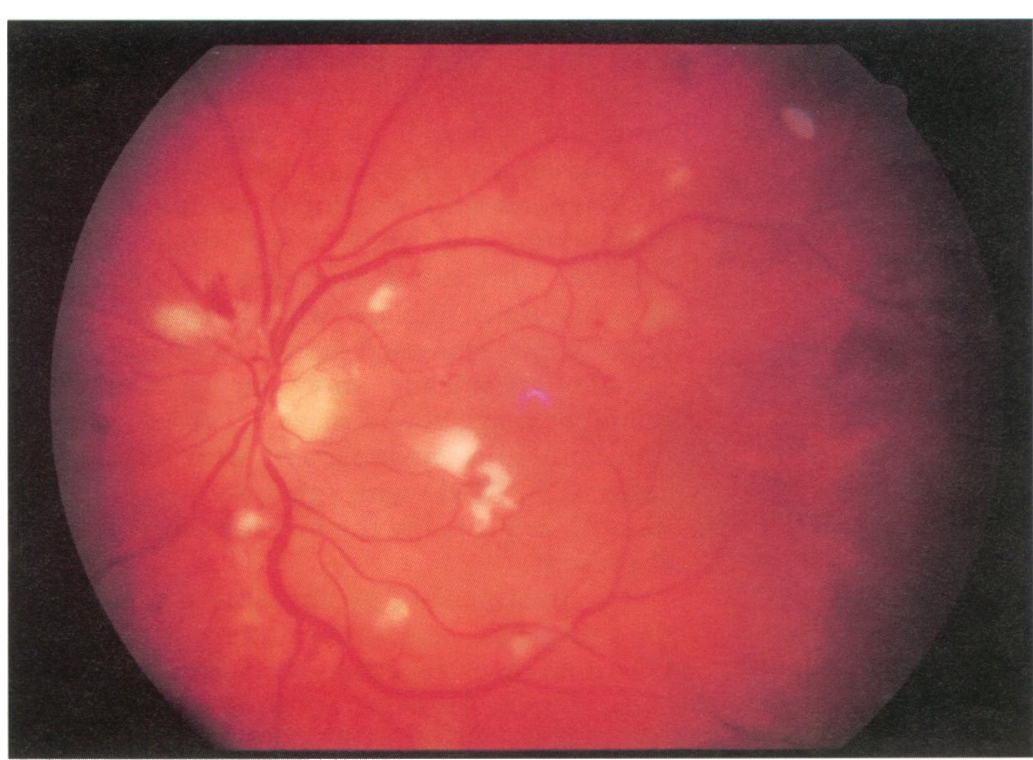

Figure 1 Retinal photograph of the left eye showing optic disc swelling, arteriolar attenuation, arteriovenous nipping, prominent cotton wool spots, and haemorrhages.

\begin{abstract}
A 43 year old intravenous drug abuser presented to the accident and emergency department with a three week history of bilateral visual loss and frontal headaches. Fundoscopy revealed bilateral retinal cot-
\end{abstract}

\section{importance of checking the blood pres- sure of all patients presenting with visual} loss.

(F Accid Emerg Med 1997;14:182-183)

Keywords: malignant hypertension; visual loss

\section{Case report}

A 43 year old man presented to the accident and emergency (A\&E) department with a three week history of bilateral blurred vision and frontal headaches. He was a long standing intravenous heroin abuser and attended because of difficulty in seeing to inject. In his past history he had received a brain contusion injury after a road traffic accident two years previously. He had recently been found to be hepatitis $\mathrm{C}$ positive, although he had not received any treatment for this. $\mathrm{He}$ was otherwise well.

On examination in the $\mathrm{A} \& \mathrm{E}$ department, his vision was found to be reduced to $6 / 24$ in the right eye and $6 / 36$ in the left eye (normal $6 / 6$ or 
better). Ophthalmoscopy revealed bilateral cotton wool spots and haemorrhages. A provisional diagnosis of cytomegalovirus retinitis was made and he was immediately transferred to the eye department for an ophthalmic opinion. His best corrected visual acuities were confirmed. There was no afferent pupillary defect. Anterior segment examination revealed no abnormalities. Examination of the retina showed bilateral mild optic disc swelling, venous dilatation, arteriolar attenuation, cotton wool spots, and blot and flame shaped haemorrhages (fig 1). The most striking findings were the large cotton wool spots involving the posterior poles including the maculae. The differential diagnosis of this fundal picture in a patient with this history is wide but is in keeping with malignant hypertension. His blood pressure was found to be $210 / 140$. A provisional diagnosis of malignant hypertension was made and the patient transferred under the care of the physicians for further management.

The patient was started on oral antihypertensives while other investigations relating to the differential diagnosis of the retinal picture and the cause of his hypertension were performed. Blood glucose, blood cultures, urinalysis, plasma viscosity, $C$ reactive protein, liver function tests including plasma proteins, full blood count, auto-antibodies including ANCA, and an HIV test were all normal. An echocardiogram revealed left ventricular hypertrophy but no vegetations and computerised tomography of the brain showed extensive oedema with no focal lesions.

His hypertension gradually came under control and subsequently his vision and retinal appearances improved. Despite extensive investigations no cause for his hypertension has been found.

\section{Discussion}

Bilateral visual loss in a man of this age is unusual, as is malignant hypertension. The differential diagnosis of visual loss and retinal cotton wool spots is considerable, and further complicated by the history of intravenous drug abuse. The most common causes of cotton wool spots include diabetes mellitus and hypertension, but other causes include severe anaemia, vasculitis, blood dyscrasias, and infection including endocarditis. ${ }^{1}$ Intravenous drug abusers can develop cotton wool spots due to embolism of infected material (including fungi and bacteria) or talc, as well as HIV, AIDS, and its associated infections. A blood pressure reading of $210 / 140$ narrows the differential diagnosis considerably.

Cotton wool spots are caused by retinal nerve fibre layer infarcts, leading to a cessation of axoplasmic flow and the accumulation of axonal material. ${ }^{2}$ Hypertension causes damage to blood vessels, mainly arterial, leading to obstruction and leakage from these vessels. Changes in the fundus include arteriolar attenuation, arteriovenous nipping and displacement, retinal haemorrhages, hard exudates, cotton wool spots, and optic disc swelling. ${ }^{2}$

Malignant hypertension can present with heart failure, hypertensive encephalopathy, renal failure, headaches, and grade III-IV hypertensive retinopathy. Initial investigations include assessment of renal function, chest $x$ ray and electrocardiogram. Treatment involves strict bed rest with a gradual reduction of blood pressure, usually with oral antihypertensives such as nifedipine. Initially, chewing a 10 mg nifedipine capsule will reduce the blood pressure over 30 minutes, followed by 10-20 $\mathrm{mg}$ of oral nifedipine eight hourly. In the unconscious patient close control of blood pressure can be attained using intravenous sodium nitroprusside. ${ }^{3}$

Despite the wide differential diagnosis and unusual presentation of this case the diagnosis was made on a simple blood pressure measurement. Subsequent extensive investigations case failed to reveal any cause for the hypertension. This case illustrates the importance of checking the blood pressure in every patient attending for visual loss.

\footnotetext{
1 Brown GC, Brown MM, Hiller T, Fischer D, Benson WE, Magarghal LE. Cotton wool spots. Retina 1985;5:206-14. Wall M, Breen L, Winterkorn J. Optic disk edema with cotton wool spots. Surv Ophthalmol 1995;39:502-8.

3 Hope RA, Longmore JM, Hodgetts TJ, Ramrakha PS. Accelerated phase (malignant) hypertension. In: Oxford handbook of clinical medicine, 3rd ed. Oxford: Oxford University Press, 1993:302.
}

Accident and

Emergency

Department, Norfolk and Norwich Hospital, Norwich

A J Cooper

\section{Accident and}

Emergency

Department,

Addenbrooke's

Hospital, Cambridge

C V Egleston

Correspondence to Dr A J Cooper, Accident and Emergency Department, Norfolk and Norwich Hospital, Brunswick Road, Norwich NR1 3SR.

Accepted for publication 4 February 1997

\title{
Accidental ingestion of Ecstasy by a toddler: unusual cause for convulsion in a febrile child
}

\author{
A J Cooper, C V Egleston
}

\author{
Abstract \\ The case is reported of a toddler who pre- \\ sented with an apparent febrile convul- \\ sion. The final diagnosis was that of \\ accidental ingestion of Ecstasy. The child \\ made an uneventful recovery. Ecstasy tox-
}

icity should be added to the list of differential diagnoses in a child presenting with fever and an unexplained seizure. ( $\mathcal{A}$ Accid Emerg Med 1997;14:183-184)

Keywords: Ecstasy; toddler; accidental ingestion 